\title{
Practice-based Research Networks (PBRNs) in the Era of Integrated Delivery Systems
}

\author{
Timothy S. Carey, MD, MPH, Jacqueline R. Halladay, MD, MPH, \\ Katrina E. Donabue, MD, MPH, and Samuel Cykert, MD
}

Practice-based research networks (PBRNs) have been in existence for several decades, and they provide one mechanism to conduct research outside of academic research centers. Two transformative changes to the practice environment pose significant challenges to the manner in which PBRNs have functioned in the past and require changes to their current activities. The widespread introduction of electronic health records and the organization of practices into often hospital-dominated integrated delivery systems change the manner in which medicine is practiced, administered, and financed. Research funders are committed to extending research into communities, although we have yet to learn how to conduct these activities efficiently. We describe a number of operational challenges to this transformation, and we also propose ways to address these challenges and improve the quality and efficiency through which research is conducted. PBRNs can ensure their relevance in the research environment by adapting to this new era. (J Am Board Fam Med 2015;28:658-662.)

Keywords: Electronic Medical Records, Practice-based Research

Practice-based research networks (PBRNs) have been used for over a quarter century to conduct research on processes and outcomes of care in community practices. ${ }^{1}$ Clinicians, researchers, and funders such as the National Institutes of Health (NIH) and the Agency for Healthcare Research and Quality recognize that PBRNs may be the best way to examine patterns of care in generalizable prac-

This article was externally peer reviewed.

Submitted 28 December 2014; revised 9 April 2015; accepted 17 April 2015.

From the Cecil G Sheps Center for Health Services Research, University of North Carolina, Chapel Hill, NC (TSC, JRH, KED, SC); the Division of General Medicine and Clinical Epidemiology, University of North Carolina, Chapel Hill (TSC, SC); the Department of Family Medicine, University of North Carolina, Chapel Hill (JRH, KED); and the North Carolina Area Health Education Centers, Chapel Hill (SC).

Funding: The project described herein was supported by the National Center for Advancing Translational Sciences (NCATS), National Institutes of Health, through Grant Award no. 1UL1TR001111.

Conflict of interest: none declared.

Disclaimer: The content is solely the responsibility of the authors and does not necessarily represent the official views of the National Institutes of Health.

Corresponding author: Timothy S. Carey, MD, MPH, Cecil B Sheps Center for Health Services Research, University of North Carolina, CB 7590, Chapel Hill, NC 27599 (E-mail: tim_carey@unc.edu). tices. ${ }^{2,3}$ In addition, patients seeking care in community practices differ from those seen in tertiary care settings in important ways. They may have fewer comorbidities, may be more likely to be from racial and ethnic minorities, and be more geographically diverse. In the past several years both the NIH and the Patient Centered Outcomes Research Institute have prioritized pragmatic clinical trials as an efficient method to conduct comparative effectiveness research in generalizable populations. These pragmatic trials seem ideally suited to PBRNs because they minimally disrupt the functioning of the clinical care setting. Such trials also focus on collection of data, when feasible, from the practice's electronic health record. ${ }^{4,5}$

Historically, PBRNs have been moderate in size (50 to 150 practices) and have been characterized by their heterogeneity. ${ }^{6,7}$ Many involve both academic and community practices, and they frequently involve safety net practices such as community health centers. Study methods, originally observational, have broadened to include intervention studies. ${ }^{8}$ In the past much data collection involved chart abstraction, collection of primary data from patient reports, and assembly of limited data from aggregated claims or electronic health information. The use of these ag- 
gregated secondary data has in the past been limited by difficulty in harmonizing data definitions across disparate platforms and the restricted number of variables available. In the past 10 years, however, 2 major factors have begun to transform how PBRNs function. The research and practice communities are now challenged to respond to the growing expectations of funders and the public to conduct clinical and health services research in a manner that is both more timely and less costly on a per-participant basis than the work that has been conducted in the past. ${ }^{9}$ These 2 factors are the spread of electronic health records (EHRs) and integrated delivery systems (IDSs).

The widespread introduction of EHRs was advanced by multiple federal initiatives. These include the HITECH act, part of the American Recovery and Reinvestment Act initiatives that started in 2009. The Office of the National Coordinator for Health Information Technology and other federal units provide technical support and financial incentives for hospitals and practices to adopt EHRs and use them to enhance patient care. Through these initiatives, the proportion of officebased practices with an EHR increased to $78 \%$ in 2013 , although half have functionality for only "basic" EHR. Larger delivery systems lead in both their uptake and the functionality of their EHRs. ${ }^{10}$ At the same time, the market of EHR vendors has undergone rapid consolidation. Ten years ago, providers chose from one of dozens of systems. Currently, a handful of vendors dominate the market. The smaller number of vendors has the potential to enhance interoperability, although many challenges remain in terms of health information exchange, the use of aggregated EHR-derived data for research, and the issues of data use and storage agreements.

A second and related transformation in clinical practice is the rise of the IDS as a method of organizing health care in the United States. Many physicians are now employed by large, often hospital-dominated health care delivery systems, or they may be under various types of management contracts ${ }^{11}$; the structure and governance of these systems is formative and likely to change over time. ${ }^{12}$ These organizations, employing salaried providers, are now no longer solely the province of staff model health maintenance organizations such as the Kaiser Permanente system. Community hospitals, extended academic health center care systems, and some provider-led organizations are increasingly employing providers and/or managing their practices. ${ }^{13}$ In the past, discussions with practices regarding participation in a given research project generally involved the lead physician(s) and the practice manager. When a practice is owned or managed by an IDS, the discussions become more complex, with involvement by an administrator from the parent organization who may or may not consider research to be part of the system's organizational mission. In addition, research projects may be perceived as competing with clinical revenue-generating missions and internal and external quality improvement initiatives. These changes in the health care delivery environment pose a challenge to current PBRNs. To fulfill their missions to improve care through engaged research, they need to adapt to this changed delivery system. Our views in this article reflect our experience with a large PBRN in North Carolina and our experience with the national NIH-sponsored Clinical and Translational Science Award consortium conducting practice-based research and pragmatic trials.

These 2 changes in the organization and delivery of primary care are linked in some ways. Choice and management of EHRs is complex, and many practices are challenged by the complexity of system choice and installation, as well as by the modifications in team roles, organization, and workflows demanded by meaningful use health information technology criteria. Large IDSs can assist with these issues, and they can also decrease EHR installation costs and management through their economies of scale. What are the implications of this increasingly organized and corporate approach to care delivery for PBRNs? Like most transformational changes, some of the implications are positive and others necessitate changes in PBRN management.

PBRNs are not static; even practices in longstanding networks may move in and out of a network, and practices may merge or change leadership. In addition, practices appropriately pick and choose which studies they want to participate in. Reasons why a practice may opt in or out of a given project include personal and professional interest, number of ongoing studies, and competing activities such as computer upgrades, staff turnover or patient-centered medical home certifications. With the rise of research studies designed specifically for single EHRs, some practices even within PBRNs may be ineligible simply because of the inability of their EHR to configure a specific prompt or order, 
or to export certain information. PBRNs have varying internal policies for committing to research, but in the past planning discussions were generally with the lead practice physician and the practice manager regarding the topics, logistics, and financing of a given project.

When practices are owned or managed by a health care system, the system generally employs an administrator, often at a vice president level, over all the owned or managed practices. The administrator may or may not be a physician. The IDS may then become the entity with which subcontracts are conducted. To conduct system-wide quality improvement and population health management, delivery systems often flow their electronic health record data into a clinical data warehouse, which transforms EHR data into a searchable, analyzable database. ${ }^{14}$ These data aggregations facilitate quality improvement work and research, allowing analyses and data transfer from dozens of practices. Data warehouses are, of course, much simpler if all the component practices use the same electronic health record, and they are evolving in their governance policies regarding data access and use for research. The researcher, however, is then tasked with convincing yet another administrator or committee of the worth of the project, although a single point of approval may add significant efficiency in terms of enhanced sample size and generalizability.

Factors such as integrated ownership and clinical data harmonized and aggregated within a data warehouse are likely to facilitate PBRN activities in several ways if the practices are all within a single IDS. The unified administrative structure of the IDS can simplify contracting and enhance the consistency of interventions. However, potential problems may include the complexity of decision making when more levels of bureaucracy are involved, and employed providers may feel increased productivity pressure. Even "light touch" research in the office may be perceived by administrators as distracting from productivity goals often measured in relative value units delivered. PBRNs need to modify their organization and their processes in this new environment, and our goal is to stimulate discussion regarding these issues. Table 1 specifies some of the challenges and potential solutions in this new era of PBRN management. Some of these changes will be positive for the conduct of community-based observational research and pragmatic trials, but other challenges may interfere with the goals of the PBRNs.

\section{Promoting PBRN Survival}

How can the research community accentuate the positives and minimize the negatives of this accelerating process? Maintaining and expanding robust clinical, quality improvement, and health services research with diverse practices and populations will take active effort on the part of researchers, clinicians, and administrators, as well as the active support of funders including the Agency for Healthcare Research and Quality, NIH, and Patient Centered Outcomes Research Institute.

Some practices, particularly federally qualified health centers and small rural practices that care for underserved populations, may remain unaffiliated with IDSs because of geography and/or programmatic funding and goals. Preserving the research mission in these practices will likely require alignment of support services with research in a manner that helps these chronically stressed organizations achieve some of their educational and patient care goals. For example, an agriculture extension model providing shared services for multiple rural practices would not only serve as a hub for research activity but could provide practice consultation regarding quality improvement and redesign activities. ${ }^{15}$ Such services could include continuing education including Maintenance of Certification credit for physicians and routine continuing education for nurses and other staff, EHR and data analytic support, patient education (in person and electronically), virtual monitoring, and other services in the mobile or Internet-based health care arena. ${ }^{16,17}$ Maintenance of Certification IV and continuing education could provide desirable incentives. ${ }^{18}$ Dissemination and implementation science for the "learning health system" can rapidly spread comparative effectiveness findings and organizational priorities.

For practices that become owned or affiliated with large IDSs, the need for alignment remains, but the target then encompasses system goals in addition to those of individual practices. PBRNs need to leverage IDS informatics and administrative processes, when feasible, to enhance research efficiency and align organizational goals when possible. When an IDS has its own quality improvement or internal research organization, the PBRN 
Table 1. Challenges and Potential Solutions to Practice-Based Research Network Research Missions in the Changed Practice Environment of Integrated Delivery Systems and Electronic Health Records

\begin{tabular}{|c|c|}
\hline Activity IDS Supports & IDS Challenges for Research \\
\hline $\begin{array}{l}\text { Provides consistent administrative } \\
\text { policies for research participation } \\
\text { across practices }\end{array}$ & $\begin{array}{l}\text { Presence of an additional bureaucratic } \\
\text { layer that requires negotiation (eg, } \\
\text { need for subcontracts vs simple } \\
\text { invoicing) }\end{array}$ \\
\hline $\begin{array}{l}\text { Clinical initiatives can align with } \\
\text { practice-based research questions } \\
\text { (eg, meaningful use, patient- } \\
\text { centered home certification, } \\
\text { maintenance of certification) }\end{array}$ & $\begin{array}{l}\text { Practice interest is lessened because of } \\
\text { pressure from the IDS to maximize } \\
\text { their clinical output }\end{array}$ \\
\hline $\begin{array}{l}\text { Priorities may support a philosophy of } \\
\text { rapid dissemination and } \\
\text { implementation }\end{array}$ & $\begin{array}{l}\text { Practices at the IDS geographic } \\
\text { periphery suffer neglect regarding } \\
\text { system integration, support of usual } \\
\text { services, and administrative } \\
\text { consideration of projects not } \\
\text { related to the system as a whole }\end{array}$ \\
\hline $\begin{array}{l}\text { Increased interest in research from the } \\
\text { IDS through the lens of a } \\
\text { "learning health care } \\
\text { organization" }\end{array}$ & $\begin{array}{l}\text { Adjacent IDSs may compete with each } \\
\text { other for clinical market share; this } \\
\text { competition could potentially have } \\
\text { the unintended effect of reducing } \\
\text { collaboration on research projects }\end{array}$ \\
\hline & $\begin{array}{l}\text { IDSs may be in direct competition } \\
\text { with PBRNs; may not see the } \\
\text { worth of PBRN work when they } \\
\text { are already connected and have } \\
\text { data }\end{array}$ \\
\hline
\end{tabular}

EHR and data warehouse

Allows data collection and analysis consistency.

Provides an additional research tool for recruitment and quality improvement interventions.
Reduced presence of safety net practices, since community health centers may not be part of the IDS and use a different EMR; this risks reducing the presence of participants with low socioeconomic status and minorities in research

Fragmentation of safety net clinic PBRNs as unique entities that are not included in studies that include other practice types

Limited staff availability, even with funding, to program EMR modifications or extract data from CDW

Lack of responsiveness to providing requested data in a timely fashion

May be reactive to external forces,
may inhibit innovative solutions
PBRN Solutions and Strategies

Develop standard governance agreements to share data across systems (eg, business agreements)

Build grant budget justification to compensate practice expenses incurred

Build in CME, maintenance of certification

Package research with practice support services (eg, EHR support, patient education, mHealth, practice facilitation, purchase and maintenance of data mapping/ harmonization products)

Engage patients and other stakeholders with the idea of existing in a continuously learning health system and how all may benefit from this approach

Engage providers and staff in publications, presentations, and pursuit of better outcomes for patients based on sound science

Initially avoid topics that might be "hot buttons" for administrators

Look for win-win grants and contracts that require collaboration with multiple systems; PBRNs bring a primary care focus and insight, and IDSs bring a hospital focus

Harmonize diagnostic, test, treatment, and utilization variables and codes across IDSs, including community health centers

Standardization of interoperability methods (data transfer among EHR systems) across IDSs

Ensure the ability of commercial EHRs to provide prompts to enroll patients in studies, as well as adjust the care process through order sets and targeted and evidence-based educational materials

Budget programmer time for all projects

Joint governance of data warehouse by care delivery and academic components of IDS

Can test novel interventions in practices that are early adopters

External grant funds may partially support such innovation.

CDW, clinical data warehouse; EHR, electronic health record; EMR, electronic medical record; IDS, integrated delivery system; PBRN, practice-based research network. 
needs to be fully engaged with these endeavors. In-kind assistance to IDS administrators may be useful, although a time commitment. The IDS can learn from the often years-long relationship the PBRN has with practitioners and their communities, potentially enhancing the adoption of quality improvement initiatives. Avoiding controversial "hot button" topics until the organizations have developed good working relationships may be appropriate. The PBRN's research and quality improvement experience can then benefit the functioning of the IDS. A particular challenge will occur when a current $\mathrm{PBRN}$ incorporates practices from more than 1 IDS. For some projects, the PBRN practices may need to be stratified by IDS to avoid administrative problems and the perception of interfering with clinical competition.

To continue their mission, PBRNs must adapt to the changing reality of practice organization and delivery. The recommendations above involve engaging the practice community, IDSs, and funders. However, equally important is the demonstration of the value of PBRNs to the IDSs. The experience of PBRNs in the rapid planning and execution of research and quality improvement, and their collaboration across sites, will provide needed infrastructure to these learning delivery systems. ${ }^{19}$ Critical as well will be collaboration across IDSs to achieve sample sizes necessary for research, and well as to assess the applicability of delivery system interventions across sites. We need much more information regarding how these very large IDSs implement evidence-based care, and PBRNs can be an important component in evaluating and improving this increasingly important component of the US delivery system.

\section{References}

1. Green LA, Hickner J. A short history of primary care practice-based research networks: from concept to essential research laboratories. J Am Board Fam Med 2006;19:1-10.

2. Heintzman J, Gold R, Krist A, Crosson J, Likumahuwa S, DeVoe JE. Practice-based research networks (PBRNs) are promising laboratories for conducting dissemination and implementation research. J Am Board Fam Med 2014;27:759-62.

3. Fagnan LJ, Davis M, Deyo RA, Werner JJ, Stange KC. Linking practice-based research networks and Clinical and Translational Science Awards: new opportunities for community engagement by academic health centers. Acad Med 2010;85:476-83.
4. Concannon TW, Guise JM, Dolor RJ, et al. national strategy to develop pragmatic clinical trials infrastructure. Clin Transl Sci. 2014;7:164-71.

5. Chalkidou K, Tunis S, Whicher D, Fowler R, Zwarenstein $M$. The role for pragmatic randomized controlled trials (pRCTs) in comparative effectiveness research. Clin Trials. 2012;9:436-46.

6. Westfall JM, Mold J, Fagnan L. Practice-based research-"Blue Highways" on the NIH roadmap. JAMA 2007;297:403-6.

7. Peterson K, Lipman PD, Lange CJ Cohen RA, Durako S. Supporting better science in primary care: a description of practice-based research networks (PBRNs) in 2011. J Am Board Fam Med 2012;25:565-71.

8. Sloane PD, Dolor RJ, Halladay J. Increasing the role of practice networks in medical research. J Am Board Fam Med 2009;22:348-51.

9. Reith C, Landray M, Devereaux PJ, et al. Randomized clinical trials-removing unnecessary obstacles. N Engl J Med 2013;369:1061-5.

10. Furukawa MF, King J, Patel V, Hsiao CJ, AdlerMilstein J, Jha AK. Despite substantial progress In EHR adoption, health information exchange and patient engagement remain low in office settings. Health Aff (Millwood) 2014;33:1672-9.

11. Welch WP, Cuellar AE, Stearns SC, Bindman AB. Proportion of physicians in large group practices continued to grow in 2009-11. Health Aff (Millwood) 2013;32:1659-66.

12. Piña IL, Cohen PD, Larson DB, et al. Framework for describing health care delivery organizations and systems. Am J Public Health. 2014;105:670-9.

13. Adler KG. Making sense of the trend toward hospital employment. Fam Pract Manag 2013;20:5.

14. Holmes JH, Elliott TE, Brown JS, et al. Clinical research data warehouse governance for distributed research networks in the USA: a systematic review of the literature. J Am Med Inform Assoc 2014;21:730-6.

15. Mold JW. A cooperative extension service for primary care in Oklahoma. J Okla State Med Assoc 2011;104:414-8.

16. Arora S, Kalishman S, Dion D, et al. Quality profile: partnering urban academic medical centers and rural primary care clinicians to provide complex chronic disease care. Health Aff (Millwood) 2011;30:1176-84.

17. Hall AK, Cole-Lewis H, Bernhardt JM. Mobile text messaging for health: a systematic review of reviews. Annu Rev Public Health 2015;36:393-415.

18. Puffer JC, Bazemore AW, Phillips RL, Beebe DK. Certification status of family physicians in the initial cohort entering maintenance of certification. J Am Board Fam Med 2014;27:581-2.

19. Institute of Medicine. Best care at lower cost: the path to continuously learning health care in America. Washington, DC: The National Academies Press; 2013. 